\title{
WHO and the Threat of Thermonuclear Holocaust
}

'Effects of Nuclear War on Health and Health Services' is a mimeographed report of the International Committee of Experts in Medical Sciences and Public Health to implement Resolution WHA 34.38, being the Working Paper A36/12 submitted to the Thirty-sixth World Health Assembly on 24 March 1983. This report of 152 pages comprises a glossary ( 3 pages), a selected bibliography (1 page), a text of 21 pages with four figures, and the reports of the nine working groups, each with its own references, and together totalling 127 pages. In the view of the International Committee, the report is not exhaustive, as, for example, 'it did not attempt to review in detail what could be done to reduce the detrimental effects of thermonuclear accidents or war.'

It is gratifying to note, however, that the World Health Assembly (WHA) has expressed its concern about the effects of nuclear war on the health of Mankind and the health establishments. Thus the World Health Organization-the Secretariat of the WHA-responded by selecting a number of eminent scientists and experts in various pertinent fields, and requested them to collect, review, and summarize, the most recent information on the possible effects of nuclear weapons' explosions on health and health services. The International Committee of Experts reached certain conclusions which they felt should have wide publicity - to draw the attention of politicians, the public, and the health profession, to the disastrous consequences which a nuclear conflict would have on the health and welfare of the people of the world. Excerpts from the conclusions of the Committee are indicated in the following:

1. 'As doctors and scientists, the members of the Committee feel that they have both the right and the duty to draw attention in the strongest possible terms to the catastrophic results that would follow from any use of nuclear weapons. The immediate and the delayed loss of human and animal life, would be enormous, and the effect on the fabric of civilization would be either to impede its recovery, or make recovery impossible. The plight of the survivors would be physically and psychologically appalling. The partial or complete disruption of the health services would deprive survivors of effective help.'

2. The Committee is convinced that there is a sound professional basis for its conclusions that "nuclear weapons constitute the greatest immediate threat to the health and welfare of mankind. It is not for the Committee to outline the political steps by which the threat can be removed, but mankind cannot be secure until that is done.'

In summarizing the reports of the working groups, the Committee drew attention to the following immediate catastrophe of nuclear explosions: 'One megaton bomb over a large city would kill more than one and a half million people and injure as many [more]. A limited nuclear war exploding twenty megaton weapons would exact a toll of about nine million dead and seriously injured, of whom more than 8 millions would be civilians. An all-out nuclear war exploding less than half the estimated present stockpiles of nuclear weapons - about 10,000 megatons - would result in more than 1,000 million deaths and 1,000 million injured people.' One has to consider also the long-term effects on the environment. The Committee stated that such a nuclear war would totally disrupt both the social and economic systems around the world, that famine and disease would be widespread, and that whatever remained of the medical services in the world could not alleviate the disaster in any significant way.

The Committee's role as stated 'was not to outline the political steps by which this threat can be removed, and the preventive therapy implemented'; their sole recommendation to WHO was that 'WHO can make important contributions to this process by systematically distributing information on the health consequences of atomic warfare and by continuing and expanding international cooperation in the field of health.

The above recommendation of the Committee gives rather a negative role to the World Health Organization, considering the enormous threat to humanity which a nuclear war would pose. If one accepts the fact that the mere contemplation of waging a nuclear war is regarded as the most serious mental or psychological disease, it behoves the WHO to have an active and more positive role in studying the 'epidemiology' of this modern disease, and in setting a strategy to combat this threat, which can be inflicted by governments of certain nations or even by individual terrorists.

\section{M.A. FARID c/o World Health Organization 1211 Geneva 27 Switzerland.}

\section{Newly-discovered Bacterium May Give Clues to Origin of Photosynthesis}

Biologists at Indiana University have discovered a kind of Bacterium that may be a living relic of the beginning of photosynthesis - one of the most significant events in the evolution of all higher forms of life, and indeed in the history of the world. The Bacterium may provide a new piece in solving the puzzle of how early life developed, the research workers reported to the National Science Foundation (NSF), which had financed the research through its Metabolic Biology Programme.

The 'new' Bacteria are photosynthetic, using energy from absorbed sunlight to obtain energy for growth. The oxygen in the atmosphere that made possible all higher forms of animals-including humans - came from green plants in the course of their photosynthesis, which is the process by which they use the energy of sunlight to synthesize sugars from carbon dioxide and water. During this process, oxygen is set free.

What gives the new Bacteria special interest is an unusual combination of properties that has never before been observed. They represent a new category of photosynthetic organisms, and their structure may contain 'molecular fossils' that could provide important clues to the origin of photosynthesis, according to the Indiana scientists. 'For the first two billion years after the Earth was formed, there was no oxygen in its atmosphere,' Dr Howard Gest, Distinguished Professor of Microbiology at Indiana University, said: 'The earth was populated by many kinds of microbes that did not need oxygen, long before certain primitive cells were first able to use sunlight as a source of energy for growth. The beginning of photosynthesis in living cells was one of the most singular events in evolutionary history. There is little doubt that the process of photosynthesis was first established in Bacteria and then gradually modifiedeventually resulting in the type of oxygen-producing photosynthesis that is now used by all green plants.'

In 1980, Dr Gest proposed a theory to account for the origin of the first photosynthetic cell. The new Bacterium 
may provide a means of testing the theory by molecular biological analysis, he said. 'The peculiarities of these Bacteria that we discovered strongly suggest that they may be of great value for tracing early biochemical evolution on the Earth,' he added.

Dr Gest and his assistant, Jeffrey L. Favinger, were about to throw out the contents of a flask-from an undergraduate's classroom experiment on photosynthetic Bacteria that had failed because of an error in preparation-when they noticed something growing near the bottom of the flask. They isolated the organism, which had been present in soil dug up by the student in front of the biology building, and realized they had discovered 'something different'. They named the new organism Heliobacterium chlorum, which translates from the Greek as something like 'sun green Bacterium'.

All green plants must have nitrogen in order to grow. Though there is plenty of nitrogen gas in the air, most plants are unable to use it and must obtain combined nitrogen from other sources, such as nitrogen-rich compounds in the soil. This is the principal reason why most crop plants need to be fertilized. But because virtually all photosynthetic Bacteria are also able to take nitrogen gas from the air and use it for growth, these Bacteria are prominent among biological systems that are being investigated by scientists suported by the NSF as part of a fundamental effort to determine how green plants might make their own fertilizer by taking nitrogen from the air.
Gest \& Favinger found that Heliobacterium has some odd characteristics. "This Bacterium is extraordinarily sensitive to gaseous oxygen. Even minute traces of oxygen completely inhibit its growth,' Dr Gest said. 'In addition, the Bacterium contains a unique form of chlorophyll, the green light-capturing pigment. A chlorophyll molecule essentially consists of four rings of atoms that are fused together, with a magnesium atom at the centre of the structure. One of the rings has a side-branch of two linked carbon atoms. In all other known photosynthetic Bacteria, this side-branch also contains one oxygen atom. But there is no oxygen atom in the side-branch of the chlorophyll in the Bacterium we discovered.'

'This absence of oxygen, together with the fact that even minute traces of oxygen prevent growth of this Bacterium, reinforces the idea that the Bacterium evolved long before there was any oxygen gas in the Earth's atmosphere-in other words, long before photosynthesis by green plants was "invented",' Dr Gest explained.

The research workers are sending batches of the Bacterium to scientists at other institutions who specialize in different areas of biochemistry and molecular biology. 'This will speed up solution of the life-style mysteries of this fascinating organism, whose ancestors were at an important crossroad in evolutionary history,' Dr Gest said.

RALPH KaZARIAN

National Science Foundation $1800 \mathrm{G}$ Street, Washington DC 20550, USA.

\section{Gasifiers-a Born-again Technology}

There is no irony in the technological lead of the Philippines and Brazil in developing gasifiers; for during World War II, when Europe's oil-starved economies were under military siege, 'gasification' powered more than one million vehicles. London buses could be seen towing stove-like gasifiers on trailers, while many big cars of the 1940s sprouted devices resembling boilers on their rear ends, and sported roof-racks full of charcoal.

Post-war supplies of cheap oil quickly killed gasification. After all, the gas is poisonous (mostly carbon monoxide), so dirty that engines need 'constant' cleaning, and not as 'hot' as gasoline-making gasified engines sluggish. Then, in the 1970 s, rapidly-rising oil prices and falling commodity prices placed oil-importing Third World countries under economic, rather than military, siege. The capital cost of a gasifier system is about one US cent higher per kilowatt/hour then that of a diesel engine, and maintenance and running costs are about three cents more. But fuel for the gasified diesel costs ten cents less per $\mathrm{kWh}$. The total cost of power with gasification is about $30 \%$ less than with straight diesel.

Successes in the Philippines and Brazil have spurred aid agencies to take a hard look at gasifiers as a means of solving the energy crisis in developing countries. Wood gas cannot help all Third World countries: in particular, regions without trees - such as Sahelian Africa or the Middle East-lack the fuel to run gasifiers. But many development experts are convinced that wood gas is a commodity whose time has come around again.

LLOYD TIMBERLAKE

Earthscan

10 Percy Street

London WIP ODR

England, UK.

\section{Oil-wells Blocked to Prevent War Damage}

Iran has blocked all but six of its oil-wells in the offshore Nowruz and Ardeshir fields with cement, virtually eliminating the possibility that future Iraq missile strikes in the area could result in increased oil pollution of the Gulf, according to reports reaching the World Wildlife Fund International. Seventy-five wells in the Nowruz field, and an unspecified number that includes all wells in the nearby Ardeshir field, have been blocked down to the seabed, according to industry sources. All these wells will eventually have to be redrilled to be put back into production, these sources said. The last wells were blocked in November 1983.

The World Wildlife Fund and other conservation groups have been alarmed at the prospect of further damage to wells that might drastically increase oil pollution of the Gulf. Pollution has already virtually exterminated the population of dugongs and sea snakes, and severely affected coral reefs, marine turtles, and other living things in coastal waters.

Wells on two platforms in the Nowruz field were still burning in November after being hit by Iraqi missiles in early March. At the former time there had been no recent missile strikes against oil-wells, but there have been continuing attacks on Iranian shipping, the oil terminal at Kharg Island, and onshore pumping and storage facilities. Offshore oil for these facilities was being produced only in the Fereidoon field, which had not been attacked. Meanwhile an international conference has been scheduled in Teheran to study the environmental effects in the Gulf of oil pollution caused by the war.

Donald Allan, Information Director World Wildlife Fund International

Avenue du Mont-Blanc

1196 Gland, Switzerland. 